\title{
Investigation of TiCr Hydrogen Storage Alloy
}

\author{
R. Pedicini ${ }^{1,2, *}$, I. Gatto $^{1}$, E. Passalacqua ${ }^{1}$, C.A. Biffi ${ }^{3}$, M. Coduri $^{3}$ and A. Tuissi ${ }^{3}$ \\ ${ }^{1}$ CNR-ITAE, Institute for Advanced Energy Technologies, Via S. Lucia sopra Contesse 5, 98126 - Messina, \\ Italy \\ ${ }^{2}$ Affiliated to Dipartimento di Fisica, Università della Calabria, Via Ponte P. Bucci, Cubo 31C, 87036 \\ Arcavacata di Rende (CS), Italy \\ ${ }^{3}$ CNR-ICMATE, Institute of Condensed Matter Chemistry and Technologies for Energy, Unit of Lecco, Via \\ G.Previati 1/E, 23900 Lecco, Italy
}

\begin{abstract}
A new reversible hydrogen storage material, based on $\mathrm{TiCr}$ metal alloy, is proposed. $\mathrm{Cr}$ and $\mathrm{Ti}$ were mixed and melted in a final atomic ratio of 1,78. Chemical-physical characterisations, in terms of XRD and SEM-EDX, were performed. The quantification of Laves phases was performed through Rietveld refinements. The atomic $\mathrm{Cr} / \mathrm{Ti}$ ratio was determined by EDX analysis and 1,71 was obtained. The $\mathrm{H}_{2}$ sorption/desorption measurements by Sievert apparatus were carried out. After different tests varying temperature and pressure, a protocol measurement was established; and a $\mathrm{H}_{2}$ sorption value of $0,4 \mathrm{wt} \%$ at $200{ }^{\circ} \mathrm{C} / 10$ bar with a fast kinetic at 5 bar ( $\Delta \mathrm{wt} \%$ of about $0,3 \mathrm{wt} \%$ ) were obtained. Hydrogen desorption measurements performed in the same conditions of $\mathrm{T}$ confirmed a totally reversible trend. A confirm of metal hydride formation was recorded by XRD, in fact, comparing X-Ray patterns before and after volumetric tests a notable difference was recorded.
\end{abstract}

Keywords: $\mathrm{TiCr}$ alloy development, morphological and crystallographic study, $\mathrm{H}_{2}$ sorption/desorption measurements, post mortem $\mathrm{H}_{2}$ sorption test characterisation.

\section{INTRODUCTION}

Hydrogen is an ideal energy carrier under consideration as a fuel for the future, such as in automotive applications. However, although hydrogen has a promising, bright future in the energy field, the application of hydrogen requires a safe and efficient storage technology.

Consequently, hydrogen storage is one of the key challenges in developing the hydrogen economy, especially in transportation. Since transportation is one of the main contributors to greenhouse gas emissions, it is important to find suitable on-board hydrogen storage solutions for such application.

Two conventional ways to store hydrogen are used: high pressure or low cryogenic temperatures. Hydrogen can be pressurized in stainless steel containers up to a pressure of 200 bars and in tanks made of composite materials up to 800 bars [1-2]. Such hydrogen compression involves a significant amount of energy $\left(2,21 \mathrm{kWh} \mathrm{kg}^{-1}\right)[3]$ and the volumetric storage density remains relatively small. The process is expensive and using hydrogen pressurized tanks onboard and/or nearby densely populated areas requires safety measures [4].

*Address correspondence to this author at the CNR-ITAE, Institute for Advanced Energy Technologies, Via S. Lucia sopra Contesse 5, 98126 Messina, Italy; Tel: + 39-090-624-277; Fax: +39-090-624-247;

E-mail: rolando.pedicini@itae.cnr.it
The alternative applied method is to use hydrogen in its liquid form [5-6]. This option seems to be more attractive since the liquefied hydrogen occupies much less space than that in pressurized form. The disadvantages are the energetically expensive liquefaction process $\left(15,2 \mathrm{kWh} \mathrm{kg}^{-1}\right)$ [3] and the requirement of thermal insulation to keep hydrogen at the very low temperature of $20 \mathrm{~K}$. In addition some amount of the stored hydrogen in liquid form will be lost due to evaporation or "boil off", especially when small tanks with large surface to volume ratio are used.

Another method is based on the use of materials able to storage hydrogen through a Physical (Physisorption) or Chemical sorption (Chemisorption).

During the physisorption, hydrogen molecules are weakly bound to the surface of the adsorbent material by van der Waals interactions [7]. The physisorption phenomenon can be an extremely fast and fully reversible process, without any $\mathrm{H}_{2}$ losses. Since the strength of adsorption interaction is very weak, low cryogenic temperatures must be applied to obtain reasonable hydrogen storage capacity, thus, only one hydrogen monolayer can be adsorbed. For this reason materials with very large specific surface area are desirable. Different types of porous compounds such as light porous carbon materials [8-9], silica based materials [10-11], zeolites [12-13] and metal-organic frameworks (MOFs) [14-17] have been investigated. Other interesting classes include composite materials [18-25]. 
Chemisorption mechanism starts with hydrogen molecules physisorption on metal surface. Due to strong interactions with the metal surface, dissociation of hydrogen molecules and atomic hydrogen surface absorption occur under certain temperature and pressure conditions [26-27].

The kinetics of this process is much slower in comparison to the adsorption of molecular hydrogen in porous materials, but atomic hydrogen in metal hydrides binds via chemical bonds with an around 10 times stronger enthalpy of formation [28]. This fact implies that higher temperatures are required in order to break the bonds and remove absorbed hydrogen from the structure.

Crucial advantage of these materials is that they possess the unique ability to absorb hydrogen and desorb it later when it is needed [29].

Metal or metallic compounds suitable for efficient hydrogen storage should have light weight and the ability to store a large amount of hydrogen by weight.

Unfortunately, for light metal hydrides hydrogen loading does not occur spontaneously at room temperature and ambient pressure conditions [30-31], moreover, depending on the applied pressure and temperature different amounts of gas can be stored. A solution could be the use of a bimetallic alloy, in which one of the metal forms a very stable hydride and the other forms a very unstable one, in this case, the intermetallic compound or alloy can form hydrides of intermediate stability.

Among metal compounds, particular attention has to be addressed towards complex hydrides such as $\mathrm{NaAlH}_{4}$ [32] and $\mathrm{LiBH}_{4}$ [33] that possess high theoretical hydrogen gravimetric capacity of $5,4 \mathrm{wt} \%$ and 18,5 wt\% respectively. On the other hand, desorption process occurring in two steps, at high temperature and with rather slow kinetics [34], is a drawback. An important breakthrough has been made doping the alanates with $\mathrm{Ti}$ that catalyses the reversible hydrogen sorption.

Recently, AB2 metal alloys have become more interesting for their high $\mathrm{H}_{2}$ storage capacities, almost comparable to compressed $\mathrm{H}_{2}$ systems [35].

One of the most studied AB2 metal alloy is $\mathrm{TiCr}$ system even if it has not been extensively studied. In fact, the thermodynamic behaviour of the $\mathrm{H}$ solid solution ( $\alpha$-phase), as well as the influence of the activation process is scarcely known. Some studies, report the reduction of the high stability of the final hydride by replacing $\mathrm{Ti}$ with $\mathrm{Zr}$ sites [36]. Other works on $\mathrm{TiCr}$ alloy have established a preliminary activation at high temperature and after this step, they found very interesting performance at $\mathrm{T}>25^{\circ} \mathrm{C}$ [37-38].

In this work a promising $\mathrm{TiCr}$ metal alloy is proposed. Quantification of $\mathrm{TiCr}_{2}$ Laves phases was performed by Rietveld refinements and 1,71 atomic $\mathrm{Cr} / \mathrm{Ti}$ ratio was found by EDX characterisation. A tests protocol for $\mathrm{H}_{2}$ sorption and desorption measurements was established and a $0,4 \mathrm{wt} \% \mathrm{H}_{2}$ absorption value was obtained operating at $200^{\circ} \mathrm{C} / 10$ bars, moreover, a fast $\mathrm{H}_{2}$ absorption kinetic at 5 bars was observed. A reversible behaviour, at $200{ }^{\circ} \mathrm{C}$, was recorded through $\mathrm{H}_{2}$ desorption measurements. After volumetric tests, XRD characterisations were carried out confirming metal hydride formation.

\section{MATERIALS PREPARATION}

Pure metals $\mathrm{Ti}$ and $\mathrm{Cr}$ were melted at their melting points [39] by means of a vacuum arc furnace (Leybold mod. LK 6/45) with a non-consumable tungsten electrode to obtain small cylindrical buttons $(30 \mathrm{~mm}$ in diameter and about $80 \mathrm{~g}$ in weight) with an atomic $\mathrm{Cr} / \mathrm{Ti}$ ratio of 1,78 (Figure 1 ). The melting furnace was equipped with a water-cooled copper crucible for avoiding the contamination of the liquid pool; the melting was done in highly pure inert atmosphere $\mathrm{Ar}$ 99,99 \% at 400 mbar pressure). Vacuum Arc Remelting (VAR) produces buttons of desired composition. Each button was re-melted for 6 times to increase its homogeneity and, finally, a purification method was carried out. This step includes: a sandblasting for surface oxide removal, stirring in ethanol and a crushing with agate mortar and pestle to obtain a powder.



Figure 1: Vacuum arc furnace and final cylindrical button. 


\section{MATERIALS CHARACTERISATION}

Compositional and microstructural analyses were carried out using a SEM (mod. Leo 1430), equipped with Energy Dispersive X-ray Spectroscopy (EDS).

Diffraction data (CuK $\alpha \lambda=1,5418 \AA$ ) were collected on a $\theta-\theta$ vertical scan diffractometer (mod. Panalytical $X$ 'Pert PRO), equipped with parallel (Soller) slits $-0,04$ rad - and a Real Time Multiple Strip detector. The generator was operated at $40 \mathrm{kV}$ and $30 \mathrm{~mA}$; slits were used with a divergence of $0,5^{\circ}$. The scans were performed in the $12-90^{\circ} 2 \theta$ range at temperature of $25^{\circ} \mathrm{C}$.

$\mathrm{PCl}$ (Pressure Composition Isotherms) were measured through Sievert's method using an automated apparatus (PCT-Pro2000 Setaram Instrument). Before the analysis all the samples were weighed. The measurements were carried out at $30^{\circ} \mathrm{C}$ and $200{ }^{\circ} \mathrm{C}$ by varying the pressure from 2 to 40 bars.

\section{RESULTS AND DISCUSSION}

The quantification phase via a Rietveld refinement was carried out, as displayed in Figure 2.

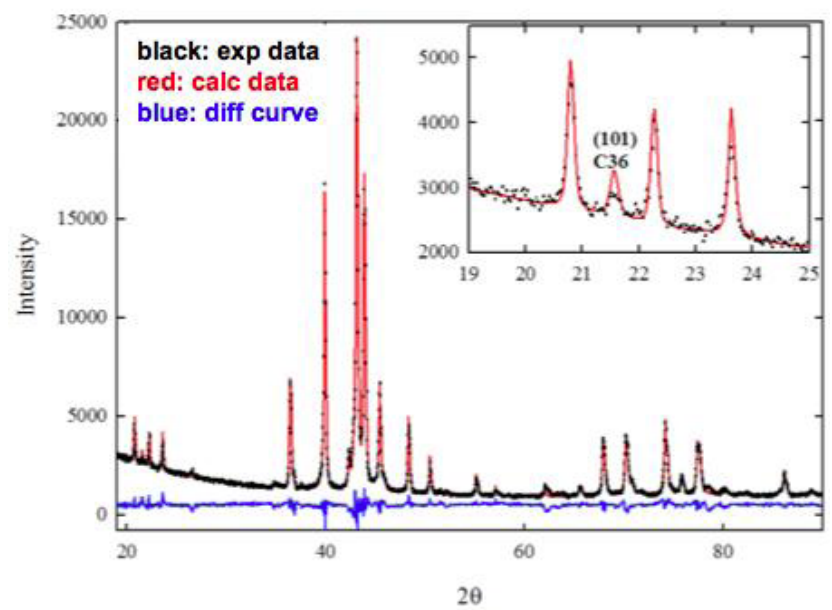

Figure 2: Rietveld refinement of the as cast material in powder form. The insert highlights the low $\theta$ region. Black circles: experimental data; red solid line: calculated pattern; blue solid line: difference curve.

At low angles (as highlighted in the insert of Figure 2) the quality of the fit between experimental and calculated data is good and it is possible to identify the different phases of the $\mathrm{TiCr}$ alloy. The signal at $\sim 21,5^{\circ}$ is a fingerprint of the hexagonal C36 phase. Since its intensity is much smaller than the nearby reflections, another phase, namely $\mathrm{C} 14$, contributes to these reflections. Then, we can affirm that the alloy is mainly composed of hexagonal phases C14 (68\%) and C36
$(30 \%)$. Instead, the fraction of cubic C15 is negligible $(2 \%)$. Further peaks were found to be consistent with the $\mathrm{Ti}_{6} \mathrm{O}$ phase. The quality of the fit decreases at high angle, with the experimental profile sharper than the calculated one. This is probably due to some chemical inhomogeneity that is reflected in the diffraction signal as a $\Delta d / d$ additive broadening.

The chemical composition of the alloy was determined using EDX analysis applied on twelve different regions of the sample. The average value for $\mathrm{Cr} / \mathrm{Ti}$ ratio resulted to be 1,71(2) very close to 1,78 , the expected theoretical atomic ratio.

Figure 3a shows a back scattered electrons SEM micrograph taken on the as cast alloy before grinding. Although it was not possible to distinguish the different Laves phases, probably for their chemical similarity, EDX analysis revealed that the dark regions consist of Ti-rich zones preferentially bound to oxygen, with a corresponding composition in the range $\mathrm{Ti}_{3} \mathrm{O}-\mathrm{Ti}_{6} \mathrm{O}$, instead, the lighter regions are composed by intermediate TiCr compositions. In order to quantify the amount of the O-rich regions, several BSE images (6 images) were taken in different regions of the samples and the fraction of the darker pixels was found to be $8(3) \%$.

Ascertained that $\mathrm{TiCr}$ intermetallic compound was obtained, the material was tested to know the real capability to store hydrogen. Usually, before the test, it is necessary a treatment for material activation when metal alloys are used [40]. This preliminary treatment consists in a hydrogen sorption test at constant $\mathrm{T}$ (or $\mathrm{P}$ ) by increasing $\mathrm{P}$ (or $\mathrm{T}$ ) step by step.

In this case, an activation test, at low temperature $\left(30^{\circ} \mathrm{C}\right)$, increasing the pressure from 2 bars until 40 bars, was performed. The hydrogen sorption trend is reported in Figure 4.

The maximum value of hydrogen sorption of about $0,7 \mathrm{wt} \%$ was reached at 40 bar even if with a really slow kinetic. The total test time was about $300 \mathrm{~h}$. When the pressure was increased at 40 bars, a changing in the sorption kinetic was observed and after $50 \mathrm{~h}$ a $\mathrm{H}_{2}$ sorption value of about 6 times higher $(0,3 \mathrm{wt} \%)$ than obtained at 20 bars, in the same period of time, was recorded. For this reason the measure was prolonged until a total time of about $140 \mathrm{~h}$.

The influence of the temperature in the kinetic absorption reaction was investigated performing a similar PCT measure at $200{ }^{\circ} \mathrm{C}$ on the already 

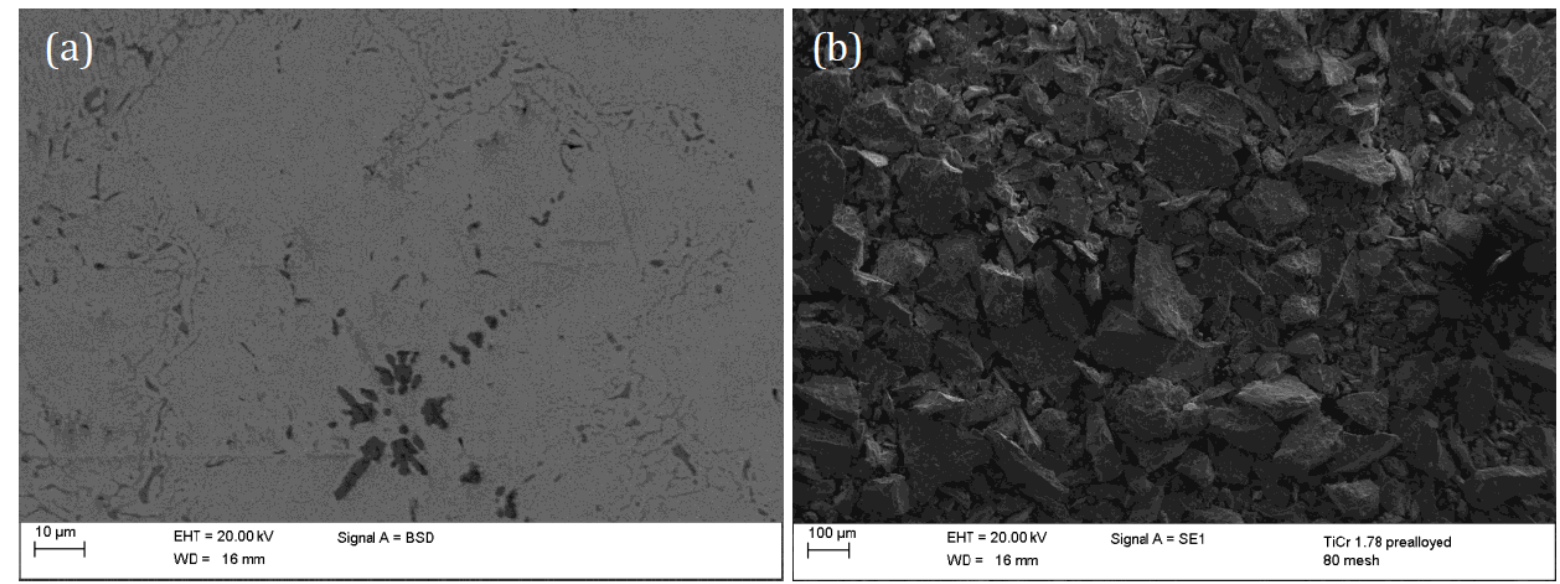

Figure 3: (a) SEM-BSE image of the bulk material before crushing into powder; (b) SEM image on TiCr powder.

activated sample, after a short desorption process (about $3 \mathrm{~h}$ ). In order to maintain one of the two parameters ( $\mathrm{P}$ or $\mathrm{T}$ ) low, the pressure value did not exceed 10 bars, as shown in Figure 5.

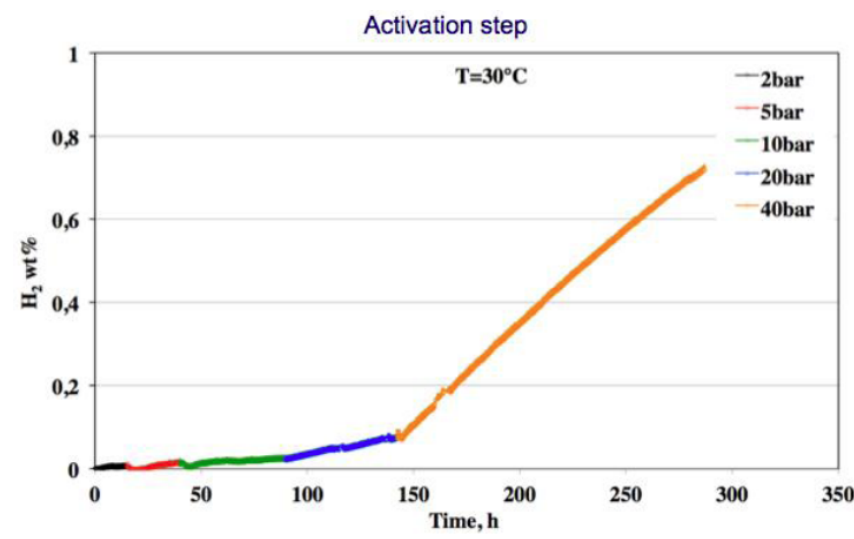

Figure 4: Activation step at $30^{\circ} \mathrm{C}$.

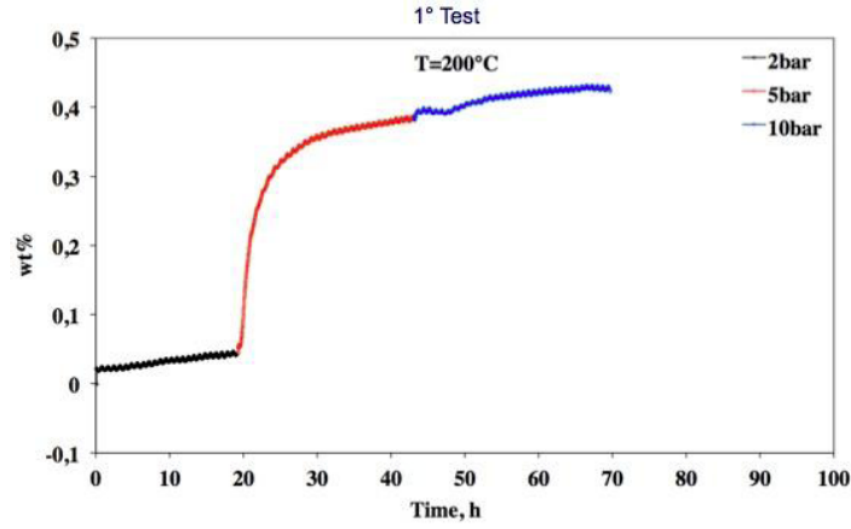

Figure 5: Hydrogen sorption tests at $200^{\circ} \mathrm{C}$.

An interesting $\mathrm{H}_{2}$ sorption trend was revealed at 5 bars, in which the kinetic reaction is faster than other two pressures. Moreover, after about $10 \mathrm{~h}$ at 5 bar the $\mathrm{H}_{2}$ sorption reaches a plateau and a further increase in the pressure (10 bar) does not lead at significant improvements.

The time and the hydrogen sorption values for each step pressure are reported in Table 1.

Table 1: Hydrogen Sorption Values and Test Time at 30 ${ }^{\circ} \mathrm{C}$ and $200{ }^{\circ} \mathrm{C}$

\begin{tabular}{|c|c|c|c|}
\hline $\mathbf{T} /{ }^{\circ} \mathbf{C}$ & $\mathbf{P} / \mathbf{b a r}$ & $\mathbf{t} / \mathbf{h}$ & $\mathbf{w t} \%$ \\
\hline \hline \multirow{3}{*}{30} & 2 & 15 & 0 \\
\cline { 2 - 4 } & 5 & 25 & 0,01 \\
\cline { 2 - 4 } & 10 & 50 & 0,03 \\
\cline { 2 - 4 } & 20 & 50 & 0,08 \\
\cline { 2 - 4 } & 40 & 140 & 0,7 \\
\hline \multirow{3}{*}{200} & 2 & 18 & 0,04 \\
\cline { 2 - 4 } & 5 & 24 & 0,38 \\
\cline { 2 - 4 } & 10 & 26 & 0,4 \\
\hline
\end{tabular}

The time of each pressure step at $200{ }^{\circ} \mathrm{C}$ is comparable so it is possible to compare the results between them.

A complete $\mathrm{H}_{2}$ desorption process was reached after about $20 \mathrm{~min}$, as clearly reported in Figure $\mathbf{6}$, in the same temperature condition.

After these preliminary tests, it seems that the best absorption conditions are $200{ }^{\circ} \mathrm{C} @ 5$ bars, while desorption process was optimised in the same $T$ condition $\left(200^{\circ} \mathrm{C}\right)$ and at 1 bar.

The total reversibility of the process has therefore been verified, even if it requires a greater number of $\mathrm{H}_{2}$ adsorption/desorption cycles $(>100)$ to affirm that this kind of material is potentially usable for store hydrogen. 




Figure 6: Hydrogen desorption tests at $200^{\circ} \mathrm{C}$.

To verify the actual interaction between metal alloy and hydrogen a post-mortem XRD analysis was performed on the material. The XRD pattern collected on $\mathrm{TiCr}$ alloy, after $\mathrm{H}_{2}$ absorption, is plotted in Figure 7 and superimposed to that of the as cast powder. XRD shows overlapped patterns, confirming the mainly hexagonal phases. The interaction with hydrogen leads to diffraction signals shifted towards lower $2 \theta$ values according to larger lattice parameters extracted from Rietveld refinements. Concerning the $\mathrm{C} 14$ phase, it expands from $4,9245(2)$ to $4,9486(7) \AA$ and from $7,9682(3)$ to $8,096(1) \AA$. On the basis of tabulated values for $\mathrm{TiCr}_{2}$-based hydrates, the crystallographic cell dimensions should correspond to a rough composition $\mathrm{TiCr}_{2} \mathrm{H}_{0.4}$ [41].

Moreover, after $\mathrm{H}_{2}$ tests the peaks become broader. This can be ascribed to residual stresses consequent after $\mathrm{H}_{2}$ interaction with the material.

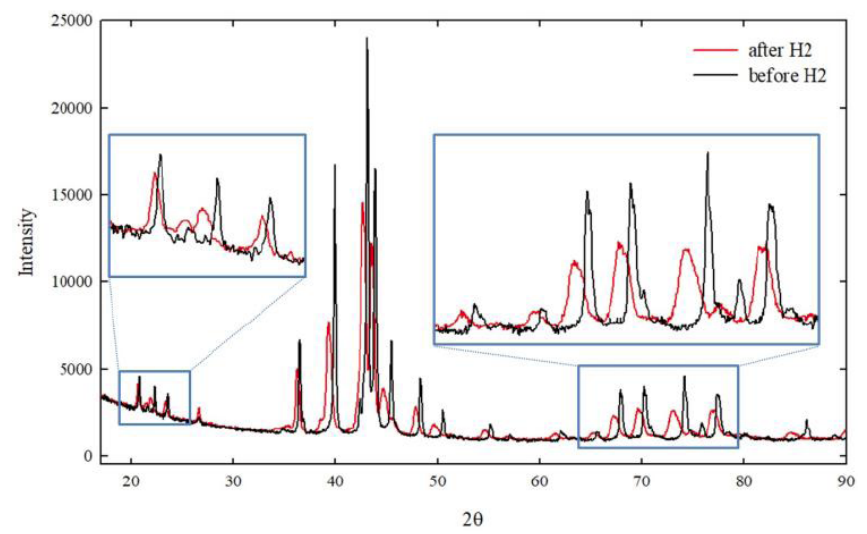

Figure 7: Experimental patterns collected before (black) and after (red) $\mathrm{H}_{2}$ abs/des curves.

Starting from the value obtained at $200^{\circ} \mathrm{C} / 5$ bar, the hydrogen volumetric capability in term of mass $(\mathrm{Kg})$ of absorbed hydrogen per volume of absorbent material $(L)$ is calculated as follows:

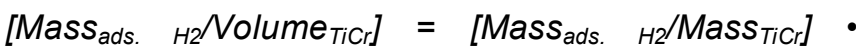
Density $_{T i C r}[1]$

in which:

Mass $_{\mathrm{TiCr}}=0,689510^{-3} \mathrm{Kg}$

Density $_{\text {TiCr }}=3,015 \mathrm{Kg} \mathrm{L}^{-1}$

Volume $_{T i C r}=$ Mass $_{T i C r} /$ Density $_{T i C r}=0,000228 \mathrm{~L}$

Because of the percentage of absorbed $\mathrm{H}_{2}$ is 0,4 wt\%, it means that the $\mathrm{H}_{2}$ absorbed in the material is $0,00410^{-3} \mathrm{Kg} \times 0,689510^{-3} \mathrm{Kg}=0,00275810^{-3} \mathrm{Kg} \mathrm{H}_{2}$.

Finally, the hydrogen volumetric capability of $\mathrm{TiCr}$ alloy is $0,00275810^{-3} / 0,000228=0,01209 \mathrm{Kg}_{\mathrm{H} 2} \mathrm{~L}^{-1}$. This value is still very far from the required DOE targets [42] for mobile application $\left(0,050 \mathrm{Kg}_{\mathrm{H} 2} \mathrm{~L}^{-1}\right.$ system) but it seems promising for further investigation.

The process for adsorption/desorption of hydrogen through the hydride formation depends on the stability of the hydride. When the hydride is highly stable, higher temperatures are required in order to break the bonds and remove absorbed hydrogen from the structure. A release of hydrogen (desorption) from the metal hydride is possible by either reducing the hydrogen $\mathrm{P}$ or increasing the $\mathrm{T}$. A smaller particle size is advantageous because the surface area is increased and the diffusion distance for dissolved hydrogen in the metal hydride bulk is decreased. For this reason, activation process during the first several cycles has to be carried out to reduce the particle size. As a consequence, in the future, particular attention has to be devoted to the activation step conditions and the material morphology.

Another problem for the application of metal-based alloys is the cyclic durability. The stability in desorption phase of the metal hydride is one important issue for its applicability. Metal hydrides invariably undergo physical and chemical degradation during prolonged hydrogen cycling. If the metal hydride can be made stable and free of impurities, the cycling stability would be greatly enhanced. Therefore, further work should therefore be considered to determine the behaviour over multiple cycles (and not assessed over one cycle), as in the real application.

\section{CONCLUSIONS}

In this work, a promising $\mathrm{Cr} / \mathrm{Ti}$ metal alloy is proposed. $\mathrm{Cr}$ and $\mathrm{Ti}$ were mixed and melted utilizing 
Vacuum Arc Melting procedure to obtain a final atomic ratio of 1,78. Chemical-physical characterization, in terms of XRD and SEM-EDX, were performed. Through EDX analyses the atomic chemical composition of $\mathrm{Cr} / \mathrm{Ti}$ was established; 1,71 ratio was obtained studying twelve different zones of the metal alloy.

The phase quantification of TiCr Laves phases was performed through Rietveld refinements. The $\mathrm{H}_{2}$ sorption/desorption measurements by Sievert apparatus were carried out. After different tests, a protocol measurement in terms of temperature and pressure was established. An $\mathrm{H}_{2}$ sorption value of $0,4 \mathrm{wt} \%$ at $200^{\circ} \mathrm{C} / 10 \mathrm{bar}$ and a fast kinetic at $5 \mathrm{bar}$ $(\Delta \mathrm{wt} \%$ of about $0,3 \mathrm{wt} \%$ ) were confirmed. Hydrogen sorption/desorption cycles measurements were performed at $200^{\circ} \mathrm{C}$ and totally reversible trend was obtained. The hydrogen volumetric capability in term of mass ( $\mathrm{g}$ ) of absorbed hydrogen per volume of adsorbent material $\left(\mathrm{dm}^{3}\right)$ is $12,09 \mathrm{~g} \mathrm{dm}^{-3}$ comparable to that of transition metals and/or rare earth alloys powders.

The interaction of $\mathrm{H}_{2}$ with $\mathrm{TiCr}$ was confirmed by $\mathrm{XRD}$ analysis after volumetric tests confirming metal hydride formation, in terms of significant increase of lattice parameters induced by the absorption process. Further investigations of the activation step and durability after multiple cycles are needed to improve the material stability.

\section{REFERENCES}

[1] Schlapbach L, Züttel A, Hydrogen-storage materials for mobile applications. Nature 2001; 414: 353-8. https://doi.org/10.1038/35104634

[2] Roh HS, Hua TQ, Ahluwalia RK, Optimization of carbon fiber usage in Type 4 hydrogen storage tanks for fuel cell automobiles. Int J Hydrogen Energy 2013; 38: 12795-802. https://doi.org/10.1016/j.ijhydene.2013.07.016

[3] Züttel A, Materials for hydrogen storage. Materials Today 2003; 6: 24-33. https://doi.org/10.1016/S1369-7021(03)00922-2

[4] Rivkin C, Burgess R, Buttner W, Hydrogen Technologies Safety Guide. National Renewable Energy Laboratory Technical Report 2015; NREL/TP-5400-60948.

[5] Xu W, Li Q, Huang M, Design and analysis of liquid hydrogen storage tank for high-altitude long-endurance remotelyoperated aircraft. Int J Hydrogen Energy 2015; 40: 16578-86. https://doi.org/10.1016/j.ijhydene.2015.09.028

[6] Lowesmith BJ, Hankinson G, Chynoweth S, Safety Issues Of The Liquefaction, Storage And Transportation Of Liquid Hydrogen: An Analysis Of Incidents And Hazids. Int $\mathrm{J}$ Hydrogen Energy 2014; 39: 20516-21. https://doi.org/10.1016/j.ijhydene.2014.08.002

[7] Züttel A, Schlapbach L, Hydrogen as a future energy carrier. Wiley-VCH, 2008 New York. https://doi.org/10.1002/9783527622894
Strobel R, Garche J, Moseley PT, Jorissen L, Wolf G, Hydrogen storage by carbon materials. J Power Sources 2006; 159: 781-801. https://doi.org/10.1016/j.jpowsour.2006.03.047

[9] Xia Y, Yang Z, Zh Y, Porous carbon-based materials for hydrogen storage: advancement and challenges. J Mater Chem A 2013; 1: 9365-81. https://doi.org/10.1039/c3ta10583k

[10] Sheppard DA, Buckley CE, Hydrogen adsorption on porous silica. Int J Hydrogen Energy 2008; 33: 1688-92. https://doi.org/10.1016/j.ijhydene.2007.12.021

[11] Pentimalli M, Imperi E, Bellusci M, Alvani C, Santini A, Padella F, Silica-Metal Composite for Hydrogen Storage Applications. Crystals 2012; 2: 690-703. https://doi.org/10.3390/cryst2020690

[12] Weitkamp J, Fritz M, Ernst S, Zeolites as media for hydrogen storage. Int J Hydrogen Energy 1995; 20: 967-70. https://doi.org/10.1016/0360-3199(95)00058-L

[13] Dong J, Wang X, Xu H, Zhao Q, Li J, Hydrogen storage in several microporous zeolites. Int J Hydrogen Energy 2007; 32: 4998-5004. https://doi.org/10.1016/j.jihydene.2007.08.009

[14] Ahmed I, Jhung SH, Composites of metal-organic frameworks: Preparation and application in adsorption. Mater Today 2014; 17: 136-46.

https://doi.org/10.1016/j.mattod.2014.03.002

[15] Furukawa $\mathrm{H}$, et al. Ultrahigh porosity in metal-organic frameworks. Science 2010; 329: 424-8. https://doi.org/10.1126/science.1192160

[16] Hirscher M, Panella B, Schmitz B, Metal-organic frameworks for hydrogen storage. Micropor Mesopor Mat 2010; 129: 3359. https://doi.org/10.1016/j.micromeso.2009.06.005

[17] Langmi HW, Ren J, North B, Mathe M, Bessarabov D, Hydrogen Storage in Metal-Organic Frameworks: A Review. Electrochim Acta 2014; 128: 368-92. https://doi.org/10.1016/i.electacta.2013.10.190

[18] Pedicini R, Saccà A, Carbone A, Passalacqua E, Hydrogen storage based on polymeric material. Int J Hydrogen Energy 2011; 36: 9062-8

https://doi.org/10.1016/j.ijhydene.2011.04.176

[19] Pedicini R, Schiavo B, Rispoli P, Saccà A, Carbone A, Gatto I, Progress in Polymeric Material for Hydrogen Storage Application in Middle Conditions. Energy 2014; 64: 607-14. https://doi.org/10.1016/i.energy.2013.11.073

[20] Germain J, Fréchet JM, Svec F, Hypercrosslinked polyanilines with nanoporous structure and high surface area: potential adsorbents for hydrogen storage. J Mater Chem 2007; 17: 4989-97. https://doi.org/10.1039/b711509a

[21] Matsuura H, Tanikawa T, Takaba H, Fujiwara Y, Production of an Alcohol-Based Hydrogen Storing Polymer. J Phys Chem A 2004; 108: 3235-7. https://doi.org/10.1021/jp037524g

[22] Matsuura L, Tanikawa T, Ushiba S, Ogawa M, Investigation of the Structure and Stability of an Alcohol-Based Polymer for Hydrogen Storage in the Form of Ions. Bull Chem Soc Jpn 2005; 78: 88-94. https://doi.org/10.1246/bcsj.78.88

[23] Cho SJ, Song KS, Kim JW, Kim TH, Choo K, Hydrogen sorption in $\mathrm{HCl}$ treated polyaniline and polypyrrole, new potential hydrogen storage media. Preprints of SymposiaAmerican Chemical Society, Division of Fuel Chemistry 2002; 47: 790

[24] Cho SJ, Choo K, Kim DP, Kim JW. $\mathrm{H}_{2}$ sorption in HCl-treated polyaniline and polypyrrole. Catal Today 2007; 120: 336-40. https://doi.org/10.1016/j.cattod.2006.09.007 
[25] Panella B, Kossykh L, Dettlaff-Weglikowsa U, Hirscher M, Zerbi G, Roth S, Volumetric measurement of hydrogen storage in $\mathrm{HCl}$-treated polyaniline and polypyrrole. Synth Met 2005; 151: 208-10. https://doi.org/10.1016/j.synthmet.2005.05.004

[26] Sakintuna B, Darkrim FL, Hirscher M, Metal hydride materials for solid hydrogen storage: A review. Int J Hydrogen Energy 2007; 32: 1121-40. https://doi.org/10.1016/j.ijhydene.2006.11.022

[27] Liu Y, Yang Y, Gao M, Pan H, Tailoring Thermodynamics and Kinetics for Hydrogen Storage in Complex Hydrides towards Applications. Chem Rec 2016; 16: 189-204. https://doi.org/10.1002/tcr.201500224

[28] Malyshenko SP, Romanov IA, Study of the Thermodynamic Properties of a Hydrogen Absorbing Alloy LaFe ${ }_{0.1} \mathrm{Mn}_{0.3} \mathrm{Ni}_{4.8}$ for Systems for Hydrogen Storage and Purification. High Temp 2014; 52: 403-10. https://doi.org/10.1134/S0018151X14020163

[29] Bhuiya MMH, Kumar A, Kim KJ; Metal hydrides in engineering systems, processes, and devices: A review of non-storage applications. Int J Hydrogen Energy 2015; 40: 2231-47. https://doi.org/10.1016/j.ijhydene.2014.12.009

[30] Eigen N, Keller C, Dornheim M, Klassen T, Bormann R, Industrial production of light metal hydrides for hydrogen storage. Scripta Mater 2007; 56: 847-51.

https://doi.org/10.1016/j.scriptamat.2007.01.024

[31] Khafidz NZAK, Yaakob Z, Lim KL, Timmiati SN, The kinetics of lightweight solid-state hydrogen storage materials: $A$ review. Int J Hydrogen Energy 2016; 41: 13131-51. https://doi.org/10.1016/j.jihydene.2016.05.169

[32] Wu R, Du H, Wang Z, Gao M, Pan H, Liu Y, Remarkably improved hydrogen storage properties of $\mathrm{NaAlH}_{4}$ doped with 2D titanium carbide. J Power Sources 2016; 327: 519-25. https://doi.org/10.1016/j.jpowsour.2016.07.095

[33] Javadian $P$, Sheppard DA, Buckley CE, Jensen TR, Hydrogen storage properties of nanoconfined $\mathrm{LiBH}_{4}-\mathrm{NaBH}_{4}$. Int J Hydrogen Energy 2015; 40: 14916-24.

https://doi.org/10.1016/j.ijhydene.2015.08.075
[34] Wang J, Ebner AD, Ritter JA, On the reversibility of hydrogen storage in novel complex hydrides. Adsorption 2005; 11: 811-16. https://doi.org/10.1007/s10450-005-6028-y

[35] Kojima Y, Kawai Y, Towata S, Matsunaga T, Shinozawa T, Kimbara M. Development of metal hydride with high dissociation pressure. J Alloys Compd 2006; 419: 256-61. https://doi.org/10.1016/j.jallcom.2005.08.078

[36] Bououdina M, Menier P, Soubeyroux JL, Fruchart D. Study

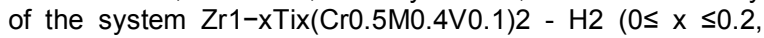
$\mathrm{M}=\mathrm{Fe}, \mathrm{Co}, \mathrm{Ni})$. J. Alloys Compd. 1997; 253-254: 302-307. https://doi.org/10.1016/S0925-8388(96)02901-5

[37] Johnson JR, Reilly JJ. Reaction of Hydrogen with the lowtemperature form (C15) of $\mathrm{TiCr}_{2}$. Inorg Chem 1978; 17: 310308. https://doi.org/10.1021/ic50189a027

[38] Johnson JJ. Reaction of hydrogen with the high temperature (C14) form of $\mathrm{TiCr}_{2}$. J Less Common Met 1980; 73: 345-54. https://doi.org/10.1016/0022-5088(80)90328-8

[39] Murray JL. The Cr-Ti (Chromium-Titanium) System. Bull Alloy Phase Diagr 1981; 2: 174-81. https://doi.org/10.1007/BF02881474

[40] Voskuilen T, Zheng Y, Pourpoint T, Development of a Sievert apparatus for characterisation of high pressure hydrogen sorption materials. Int $\mathrm{J}$ of Hydrogen Energy 35; 2010: 10387-95. https://doi.org/10.1016/j.ijhydene.2010.07.169

[41] Imoto H, Sasaki M, Saito T, Sasaki Y, Equilibrium, X-Ray, and $1 \mathrm{H}-\mathrm{NMR}$ Studies of the $\mathrm{ZrCr}_{2}-\mathrm{H}$ System. Bulletin of the Chemical Society of Japan 1980; 53: 1584-7. https://doi.org/10.1246/bcsj.53.1584

[42] https://energy.gov/sites/prod/files/2017/05/f34/fcto_myrdd_ta ble_onboard_h2_storage_systems_doe_targets_tidv_1.pdf. 